\title{
STANDARDIZATION AS AN ARENA FOR OPEN INNOVATION
}

\author{
Endre Grøtnes \\ Department of Informatics \\ University of Oslo \\ Oslo, Norway
}

\begin{abstract}
This paper argues that anticipatory standardization can be viewed as an arena for open innovation and shows this through two cases from mobile telecommunication standardization. One case is the Android initiative by Google and the Open Handset Alliance, while the second case is the general standardization work of the Open Mobile Alliance. The paper shows how anticipatory standardization intentionally uses inbound and outbound streams of research and intellectual property to create new innovations. This is at the heart of the open innovation model. The standardization activities use both pooling of $R \& D$ and the distribution of freely available toolkits to create products and architectures that can be utilized by the participants and third parties to leverage their innovation. The paper shows that the technology being standardized needs to have a systemic nature to be part of an open innovation process.
\end{abstract}

Keywords Open innovation, standardization, telecommunication, Open Mobile Alliance, Android

\section{INTRODUCTION}

There have been different views on the relationship between standardization and innovation. As David and Greenstein (1990, p. 12) summarized,

...early standardization of products may encourage innovation in complementary technology and organizations, and it may promote subsequent incremental innovation designed to perfect the original technology.... On the other hand de

Please use the following format when citing this chapter:

Grøtnes, E., 2008, in IFIP International Federation for Information Processing, Volume 287, Open IT-Based Innovation: Moving Towards Cooperative IT Transfer and Knowledge Diffusion, eds. León, G., Bernardos, A., Casar, J., Kautz, K., and DeGross, J. (Boston: Springer), pp. 343-359. 
facto standardization may prematurely close off basic exploration of technological opportunities in a wide area... discouraging further investment in nonincremental innovation.

Since then, the standardization process has changed. Standardization has gone from a process where the market or an organization chose between different existing products in hindsight (reactive or ex post standardization) to a process where companies pool their resources to create new products and services (anticipatory or ex ante standardization). Participation in standardization has become an extension of the firm's internal research and development process, and is in many cases a vital part of a product development cycle (Weiss and Sirbu 1990) and innovation in the firm.

Anticipatory standards define future capabilities for information and comunications technologies in contrast to recording and stabilizing existing practices or capabilities de facto (Lyytinen et al. 2008). Anticipatory standardization is a collaborative effort to create technologies or services that do not yet exist. The participants bring with them their knowledge, R\&D capabilities, and intellectual property. Together they create specifications for new technologies, services, procedures, systems, or architectures. These specifications become available for all participants, who can use them to create new innovations. The specifications themselves are also innovations. The standardization process is no longer a choice between existing technologies, but an innovation process where new technologies, services, procedures, systems, or architectures are created from the different parts that each participant brings into the process.

One area where standardization has been essential for innovation is the mobile telecommunication industry (Tilson and Lyytinen 2006). Here, common development and sharing of R\&D capabilities and intellectual property has happened on a large scale (Bekkers et al. 2002). The mobile telecommunication industry is a multi-sided market where actors have to cooperate to get new products into the market (Armstrong 2006). The sector has gone from a national to a regional to a global market, and in this setting no actor is so dominant that they can set a standard or introduce a new technology unilaterally (Steinbock 2005). Introduction of new mobile services needs some coordination and cooperation. This cooperative effort of creating and bringing new mobile services to the market is taking place within standardization organizations, so the innovation is also taking place within the standardization organizations. The argument brought forward in this paper is that anticipatory standardization in mobile communication is an open innovation process, and that the systemic nature of the technology being standardized makes it suitable for an open innovation process.

This paper will look at anticipatory standardization and the innovation process and compare two standardization initiatives that aim to create new mobile services. The two initiatives are the Android project from Google and the Open Handset Alliance, and the work of the Open Mobile Alliance. The paper will give insights into the question: How can anticipatory standardization act as an arena for (open) innovation within the mobile telecommunication industry? The paper will mainly add to the research on interorganizational relationships in open innovation (Maula et al. 2006; Simard and West 2006; Vanhaverbeke 2006; Vanhaverbeke and Cloodt 2006) and expand the literature on innovation and the work of international standardization organizations in the mobile sector (Cargill 1989; Funk and Methe 2001; Hawkins 1999; Schmidt and Werle 1998; Tilson and Lyytinen 2006). 
The rest of the paper is structured as follows: In the next section, the open innovation model is introduced. Section 3 presents the Android standardization initiative and the work of the Open Mobile Alliance. It also presents the research methods used and a comparison between the two standardization activities. Section 4 discusses the findings in the two cases and section 5 draws some conclusions.

\section{OPEN INNOVATION}

Open innovation is a new way of thinking of innovation for firms, where they explicitly cooperate with others to create new innovations (Chesbrough 2003). Open innovation indicates a shift in how innovation processes are perceived and conducted by firms and how products are brought to market. There has been a shift from a closed to an open model. In the closed model, R\&D was conducted within the boundaries of the firm and the firm was the one that exploited the innovations and brought them to market. The knowledge to innovate resided in the firm. In contrast to closed innovation, the open innovation model generally believes that knowledge is widely distributed and can be found outside the firm. Open innovation is a paradigm (model) that assumes that firms can and should use external as well as internal ideas, and internal and external paths to market, as they look to advance their technology (Chesbrough 2006).

Open innovation is about creating new inbound as well as outbound flows of knowledge to leverage the firm's innovation capabilities. In this process, firms should look for new sources of knowledge and new markets and outlets for their existing product and intellectual property rights, and collaborate with others, including customers, rivals, academics, and firms in unrelated industries in the process. Open innovation can be thought of as systematically encouraging and exploring a wide range of internal and external sources for innovation opportunities, consciously integrating that exploration with the firm's capabilities and resources, and broadly exploiting those opportunities through multiple channels (West and Gallagher 2006).

In open innovation, there is an inbound flow of external knowledge and intellectual property into the research and development process of the firm and also an outbound flow of knowledge and intellectual property so others can benefit from the discoveries of the firm. A novelty in the open innovation model is the explicit use off both inbound and outbound streams of knowledge. In the closed model, innovations that firms did not exploit themselves often just "sat on the shelf," unused (Chesbrough 2003). There were no explicit outbound flows of intellectual property; the only way to market was through the firm. The attractiveness of open innovation as a business strategy is the way it leads to exploiting the benefits from inbound ideas from outside the firm and exporting intellectual property (IP) that thus far has been unused (Dodgson et al. 2006). IP is a key factor for the outbound and inbound flow of technology. Without some form of protection and a way to sell their technology, firms would not have a way of appropriating value from their inventions and there would be no case for open innovation (West 2006).

Two approaches for exploiting internal R\&D through external channels are (1) spinouts or licensing of products to others and (2) pooling of R\&D with others. Both are instances of open innovation (West and Gallagher 2006). The pooling of R\&D is what happens in anticipatory standardization, where the participants brings their IP, 
technology, and knowledge into the process and for the most part agree to make the technology available on reasonable and nondiscriminatory terms. The nondiscriminatory part is essential since all participants then can use the contributed technology.

One can view open innovation as a kind of collaborative R\&D process, where firms cooperate to develop new technologies. The aim is to combine external and internal ideas into systems and architectures. One central point for open innovation is the role of the business model. Open innovation is based on business models that create overall value for all participants. Each firm must find some way to claim (internalize/capture) some portion of that overall value. It is no longer just about getting the innovation to market first but also about building the best business model to exploit the innovation. It could be that licensing the new technology is just as smart as producing the product yourself. Here lies a part of innovation that has often been overlooked but is in focus in open innovation: finding the best path to market for the product outside of the firm's boundaries and control. In open innovation, the firm intentionally loses a little of the control over the innovation process (van de Vrande et al. 2006; West and Gallagher 2006).

Open innovation can at first sight be quite similar to open source but the two are not the same. Open source is one way of doing open innovation (von Hippel and von Krogh 2006). Both are about sharing of ideas and collaborating to develop new products, but open innovation explicitly incorporates the business model and the creation and capture of value. For open source, open standards, and open innovation, the open part refers to collaboration by firms in producing some shared output (West 2007). Open innovation is not open in the same way as the two others. Open innovation brings a note of realism to the discussion of open standards (and open source) by putting the capture of value onto the center stage.

One goal of open innovation is to create new value for the participating firms through the innovation process. This is quite similar to the notion of "value networks" (Christensen and Rosenbloom 1995), where firms find partners both horizontally and vertically in networks instead of only cooperating with firms within the vertical value chain (Hess and Coe 2006; Li and Whalley 2002; Teece 1986), or "innovation networks" (Dittrich and Duysters 2007), where firms develop strategic alliances with other firms to leverage their R\&D. Interorganizational relations, cooperation, and networking are an important dimension of open innovation (Vanhaverbeke 2006). With both inbound and outbound flows of technology and knowledge, there must be some sort of cooperation and networking between firms in open innovation. Simard and West (2006) have developed a taxonomy of network ties that enable open innovation. They have made a distinction between formal and informal ties and deep and wide ties. Deep ties enable a firm to capitalize on its existing knowledge while wide ties enable a firm to exploit new technologies and markets.

According to von Hippel (1988), the sources of innovation differ greatly. He assumes that the innovators are distributed among different functional sources. He categorizes these sources according to what benefit they get from a given product, process, or service. The categories he ends up with are (1) users, (2) manufacturers, and (3) suppliers. These are all sources of innovation. He also shows that the sources of innovation vary from industry to industry. Firms can take on different functional roles in different settings; sometimes they can be manufactures and other times users or suppliers. In his research, von Hippel focuses on two modes of innovation: the cooperation 
in R\&D by rival firms through informal trade of technical know-how and the concept of lead users. Lead users are users that face needs that are general in the market, but face them earlier than others, and they are positioned to benefit significantly by obtaining a solution to those needs. Von Hippel's models are an antecedent to the inbound flow of innovations part in the open innovation model.

The open innovation paradigm has received input from different research streams or perspectives (Gassmann 2006). Some of them are globalization of innovation, outsourcing of R\&D, early supplier integration, user innovation, and external commercialization of technology. Delving into open innovation raises a number of issues: the type of industries and organizations suited for open innovation (Chesbrough and Crowther 2006), the interorganizational context of open innovation (Vanhaverbeke 2006), how users can contribute to open innovation (Piller and Walcher 2006; Prugl and Schreier 2006), how open innovation should be managed (van de Vrande et al. 2006), the use of technology in promoting open innovation (Dodgson et al. 2006), and the similarities and differences between open source and open innovation (von Hippel and von Krogh 2006; West and Gallagher 2006). This paper focuses on the work of new types of organizations and interorganizational networks that utilize some form of open innovation to create new technologies and services.

The open innovation model can be conceptualized as having inbound streams of knowledge, IP, and innovation generated externally and outbound streams of knowledge and intellectual property that are generated internally (see Figure 1). Binding it all together are business models that show how firms can innovate and generate overall value. For the individual firm, it is essential to find some way to capture value from the overall value generation. In open innovation, firms often build systems or architectures where the different parts interlink but can be developed independently. They can then compete on providing the best components too the overall architecture or they can provide enhancements to the architecture. This can be viewed as an indication that open innovation might benefit from and thrive in an environment where the technology to be developed has a systemic character.

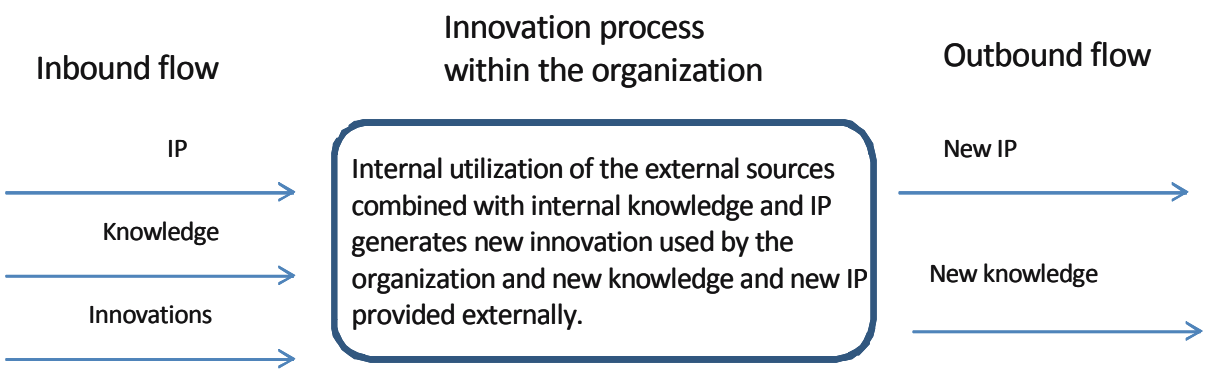

Figure 1. The Open Innovation Process 


\section{CASE DESCRIPTIONS}

In this section, the two cases are presented and some key features of their process compared. Both are from the development of mobile services in the mobile telecommunication industry. The first case is the Android project, focusing on the development of mobile applications, the second case is the work of the Open Mobile Alliance, creating general standards for new mobile services like MMS, push-to-talk over Cellular and mobile IM.

\subsection{Research Methods}

The research is based on a mixed method approach (Creswell 2003). The data and the observations were interpreted based on the author's previous knowledge and experience using an interpretivist approach (Schwandt 1994). The Open Mobile Alliance (OMA) case is based on participatory observation in the period October 2006 through December 2007. More than 20 interviews with different participants and studies of the OMA members' archives were conducted. The Android project is newer and the data collection is based on archive studies, some e-mail correspondence with Google, and interviews with some of the actors that participated in both OMA and the Android project.

The two cases were chosen because they are part of the highly dynamic mobile domain and show in different ways how open innovation takes place within different standardization initiatives.

\subsection{The Android Project}

In November 2007, Google launched the Android platform publicly with backing by the Open Handset Alliance.

The Android platform is a complete mobile phone software stack including an operating system, middleware, and key applications. The Android platform will be made available as open source software and will be licensed under the Apache v2 license. Android has been complemented with a software development kit that makes it possible for third-party developers to develop applications for the Android platform. Android is designed so developers can access core mobile device functionality through standardized APIs. One distinguishing feature of Android is that it does not differentiate between the phone's basic and third-party applications. The idea is that all applications can be modified or replaced. The Android platform was built from the ground up and many of the initial members of the Open Handset Alliance have contributed some of their intellectual property to the project.

The Open Handset Alliance had, at the launch, 34 members including companies like Google, Intel, Motorola, and Sprint. The majority of the mobile industry value chain is represent in the Open Handset Alliance. It consists of operators, handset manufacturers, semiconductor manufacturers, application providers, and some content providers. Content providers from the music and film industry are not present. The members in the Open Handset Alliance say they have joined forces to accelerate innovation in mobile telecommunication. 
At the launch, the chairman of Google said, "A fresh approach to fostering innovation in the mobile industry will help shape a new computing environment that will change the way people access and share information in the future" (OHA 2007)

Android is an architecture or a platform upon which other applications can be built (see Figure 2). It is an operating system for advanced mobile phones and competes with other operating system initiatives like Symbian and Windows mobile that can be licensed by handset manufacturers. It also competes with closed offerings like the iPhone from Apple and Blackberry from RIM.

Android depends on third-party applications developers to create applications that make it stand out from the other operating systems/platforms. To help in the development of new applications, Android has an accompanying software development kit that developers can use to develop applications for Android. To attract developers, Google has launched the Android developer challenge, which will award developers of applications on the Android platform $\$ 10$ million in prizes for the best applications. The idea behind the challenge is to inspire developers to create new and innovative applications for the mobile phone.

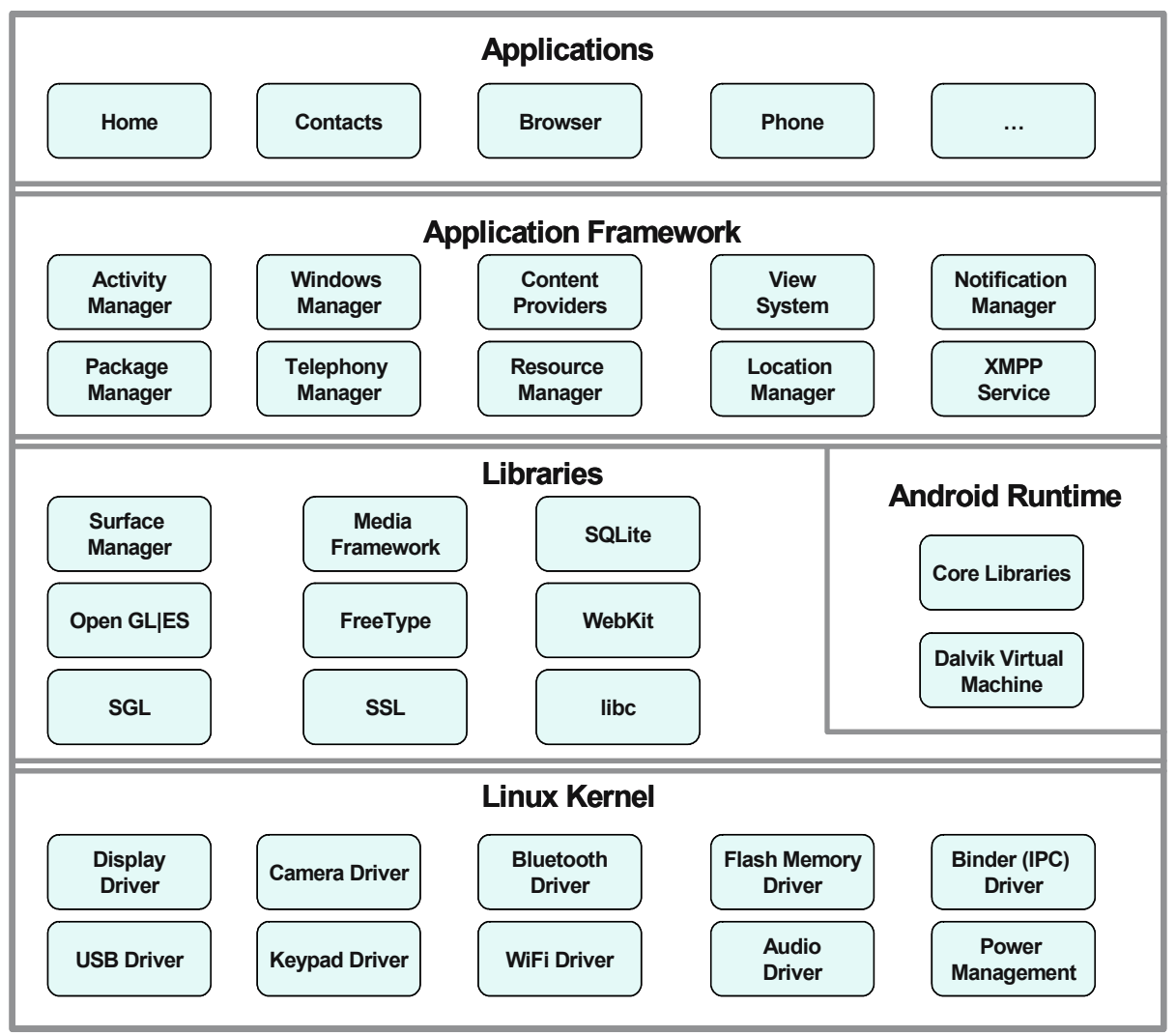

Figure 2. The Android Architecture (as presented by the Android Project; http://code.google.com/android/what-is-android.html) 
The use of a toolkit for development of enhancement to a product can be viewed as part of an open innovation strategy and has been used in game development (Prugl and Schreier 2006) and to customize and personalize product offerings (Piller and Walcher 2006).

Applications for Android are developed in Java and run on Dalvik, a custom-made virtual machine that runs on the handset. Third-party developers have access to the same APIs as the original developers of Android. The development kit gives developers access to the same set of libraries as were used for the development of the core components.

Android relies on Linux version 2.6 for core system services such as security, memory management, process management, network stack, and driver model. The kernel also acts as an abstraction layer between the hardware and the rest of the software stack. Android is not the only mobile operating system or development platform based on Linux. Examples of other Linux-based platforms are LiMo from the LiMo Foundation and Qtopia from Trolltech.

As seen in the architecture, the Android platform provides a set of application frameworks that can be used to develop applications. Android is designed for easy reuse of components. Any developer can alter or replace any application. This gives Android a systemic character. The Apache v2 license also makes it possible for developers to close the source and make proprietary offerings. According to the alliance, this will make it possible for operators and handset manufacturers to differentiate their product offerings by adding proprietary functions or by changing the entire appearance of the phone.

One main goal of the Open Handset Alliance is to sell more handsets based on the Android platform through the availability of new and innovative applications. The thought is that appealing new applications will drive up the usage of mobile services and create higher revenue for the operators. The hope is that the Android platform will create higher overall value than the competitors so operators, manufacturers, and application vendors will be attracted to the platform. Given that the platform is free, the development cost for handset and chip manufacturers might also be lower than for other platforms. Google does not and will not explicitly state how they are going to make money on this, but the general thought in the marketplace is that Google will make money by providing advertisements to the mobile users (Helft and Markov 2007), just as they do on the Internet.

The applications developed for Android can be made available as open source or they can be offered as proprietary applications. This is up to the business model of the developer.

\subsection{The Open Mobile Alliance}

The Open Mobile Alliance is a consortium with a goal of developing standards for third generation $(3 \mathrm{G})$ mobile telecommunication networks service enablers (standards). OMA was formed in June 2002 by the merger of WAP Forum and the Open Mobile Architecture Initiative, and is today the largest standardization consortium in the mobile industry domain. OMA members span the whole mobile industry value chain including operators, manufacturers, IT vendors, and content providers. This is also evident in the OMA "Memorandum and Article of Association" (OMA 2005), which distinguishes 
between four categories of companies: operators, wireless vendors, IT/application/ software vendors, and others (content media, financial and/or service providers, and others).

OMA typically specifies new functionality and services for mobile devices, like device management, data synchronization, messaging services (MMS, IM, PoC, mobile e-mail), location and presence services, broadcast services, and digital rights management (DRM). Most of the specifications are frameworks for creating new end-user services or better management of mobile devices. OMA provides enablers that can be used to create new end-user services. The members compete on implementing these enablers.

Membership in OMA is open for all. There are four different membership levels: sponsor, full, associate, and supporter. Sponsor, full, and associate members can provide requirements to the specification processes and negotiate the content of the specifications, while only the two highest levels, sponsor and full members, are allowed to vote in OMA and agree on the final outcome of the specification process. The last level, supporter, is only allowed to comment on specifications.

Specification in OMA goes through different stages (see Figure 3). First, a new idea is generated and agreed upon, then the requirement for the new service is specified before the technical details and the overall architecture are specified. All specifications have an architecture where the connections to other enablers are shown. This makes it possible to reuse existing enablers in new specifications. The architecture and specifications have a systemic nature. The following sample from the converged messaging specification in OMA (2008, p. 12) illustrates the reuse of components:

The CPM Enabler is realized as enabling framework for communication services building over a client-server architecture concept. It interacts with other network elements and re-uses functions or technologies specified by other OMA Enablers and non-OMA specifications.

In OMA, the members provide their technology and intellectual property rights (IPR) as input to the specification process. All members must use reasonable endeavors to inform about essential IPR they might have related to the prepared specification. This is informed at the start of every session in a face-to-face meeting or teleconference. The OMA members must also agree to license their IPR on reasonable and nondiscriminatory terms, a RAND policy, that is quite similar to the IPR policy of the European Telecommunications Standards Institute (ETSI). RAND policies are one of the most- used IPR policies today in telecommunication (Simcoe 2006).

The OMA process is based on consensus and takes place within working groups. The participants strive to agree on the content of the requirements, architecture, and the technical specifications. In case of disagreement, it is possible to vote. OMA has a twothirds majority rule, but this is seldom used. In the specifications, firms try to get their

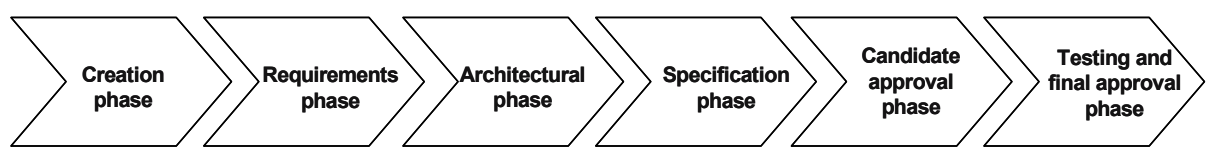

Figure 3. The OMA Standardization Process 
essential IPR into the specifications or they try to make use of external components they control in the crafting of the architecture. The specifications in OMA are often highlevel, making it possible to implement them in different ways. The specifications are also "bearer agnostic": they should work on top of any underlying network. The architectures and enablers are independent of operating systems and are based on open standards, protocols, and interfaces and are not locked to proprietary technologies. The specifications are modular and components are used in different settings to avoid the silo effects of many current services. For example, the charging enabler can be used by any new service that is created.

The membership and participation in OMA is large. In 2007, more than 500 individuals participated in each of the 6 face-to-face meetings that OMA held. OMA also has a large liaison activity that involves more than 30 other standardization activities. OMA tries to make their specifications available to the largest possible audience. They also use specifications from other organizations like IETF, 3GPP, and 3GPP2 as building blocks for their own specifications.

OMA has an inbound flow of IPR, technological know-how, and specifications both from the members and other standardization organizations. They use this input to create new and innovative specifications. They then disseminate the specifications as widely as possible so that anyone with the technological capability can use the specifications to implement actual technical solutions. The innovation first takes place within the working groups, where new ways of using technology are specified. The innovations are conceptualized in the specifications. Others then can create even newer innovations based on the available specifications. The firms in OMA compete on implementation but cooperate on the specification. The work in OMA is a collaborative R\&D process. As one member of OMA expressed it,

There has been a shift in standardization work. Previous standards were developed after the implementation of the product. Today standardization has become almost research and development. You come into a standardization organization with ideas. The ideas are refined in talks with others and then the standards are developed. The development of the product happens at the same time as the standard is developed.

The work in OMA is an open innovation process where the members and other standardization organizations provide technical know-how, IPR, and specifications, then there is a collective R\&D process of creating architectures, frameworks, and specifications within the working groups. The output of the innovation process is specifications that the participants and others can use as a starting point for their own innovations.

The standards specified in OMA can be implemented, commercialized, and taken to market in many different ways. There are no restrictions on how the standards are used as long as the specifications are adhered to and the license fees are paid.

\subsection{A Brief Comparison of the Two Cases}

In the two cases, the types of firms that participate are categorized as operators, manufacturers, application vendors, or others. This can be transferred to von Hippel's 
Table 1. The Distribution of Types of Firms in OMA and Android

\begin{tabular}{|l|c|c|c|c|c|}
\hline \multicolumn{1}{|c|}{ Organization } & $\begin{array}{c}\text { Total } \\
\text { Members }\end{array}$ & Operators & $\begin{array}{c}\text { Chip and } \\
\text { Handset } \\
\text { Manufacturers }\end{array}$ & $\begin{array}{c}\text { Application } \\
\text { Vendors }\end{array}$ & Others \\
\hline $\begin{array}{l}\text { Android and the Open } \\
\text { Handset Alliance (initial } \\
\text { members) }\end{array}$ & 34 & $7(21 \%)$ & $13(38 \%)$ & $10(29 \%)$ & $4(12 \%)$ \\
\hline $\begin{array}{l}\text { The Open Mobile Alli- } \\
\text { ance (voting members }\end{array}$ & 118 & $35(30 \%)$ & $46(39 \%)$ & $31(26 \%)$ & $6(5 \%)$ \\
\hline
\end{tabular}

(1988) categories of users, manufacturers, and suppliers. The operators are users, the manufacturers are (of course) manufacturers, and the application providers are suppliers. The last group, others, includes commercialization firms, finance institutions, consultants, research organizations, and content providers. If we look at the numbers, we can see that the relative numbers of operators are higher in OMA than in the Android project, but the distribution of manufacturers and application vendors is relatively similar (see Table 1).

Both use multiple sources of knowledge and IP to create their products. Both define architectures with systemic characteristics. Both let others use their end result for further innovation. These are typical traits of open innovations, so both are examples of open innovation processes. They differ in how open they are for initial participation and how further innovation can take place. OMA has more open participation and the use of IP is negotiated within the consortia. Licenses to use the IP, and thereby being able to produce products based on the specifications, are granted on reasonable and nondiscriminatory terms (RAND). Firms that are part of the process have an advantage in the development of products based on the specifications since they have better knowledge of the working of the specifications. The competition is in the provision of the different components within the architecture. The Open Handset Alliance provides their end product as open source. The idea is that third parties can innovate on top of the architecture. In Android the main innovators are third parties, while in OMA the main innovators are the participating firms (see Table 2).

Table 2. A Comparison Between OMA and the Android Project on Central Issues

\begin{tabular}{|l|l|l|}
\hline \multicolumn{1}{|c|}{ Issue } & \multicolumn{1}{|c|}{ OMA } & \multicolumn{1}{c|}{ Android } \\
\hline $\begin{array}{l}\text { IPR and licensing } \\
\text { (Outbound flow) }\end{array}$ & RAND & Open Source \\
\hline Initial participation & Open participation & Participation limited to partners \\
\hline End result & Technical specifications & Implemented architecture/toolkit \\
\hline Inbound flow of IP & $\begin{array}{l}\text { Open for all. Use of IP } \\
\text { negotiated within consortia }\end{array}$ & Partners provide IP \\
\hline $\begin{array}{l}\text { Systemic character of } \\
\text { innovation/specification }\end{array}$ & Yes & Yes \\
\hline Main innovation process & Pooling of R\&D & Provision of third party toolkits \\
\hline $\begin{array}{l}\text { Types of further } \\
\text { innovation/competition }\end{array}$ & $\begin{array}{l}\text { Innovation within the } \\
\text { architecture }\end{array}$ & Innovation on top of architecture \\
\hline Main innovators & Participating firms & Third parties \\
\hline Open innovation process & Yes & Yes \\
\hline
\end{tabular}




\section{DISCUSSION}

Opening up the innovation process is about creating environments for innovation outside the boundary of the firm. These environments act as common grounds for all participating actors. One such arena can be different standardization organizations. Another arena can be different open architectures that all interested parties can use to develop new technology and services. The open Internet architecture is one such example. Such open common architectures have been called innovation commons. Lessig (2002) argues that such innovation commons, where all interested parties can develop new services on top of the same architecture/infrastructure, generate more innovation than closed systems, where only the IP holder can add functionality. This is the same message that the open innovation model gives. Maula et al. (2006) argue that a systemic character of innovation acts as a driver for open innovation processes. A systemic innovation is an innovation that needs specialized complementary assets before it can be brought to market. Examples of such systemic innovation systems are the Internet and $3 \mathrm{G}$ mobile phone systems. Because of the complexity in systemic innovations, vertical innovation is rarely an option, and the innovation process often becomes a collaborative process (Maula et al. 2006). This is the case for $3 \mathrm{G}$ mobile systems. Here, innovating companies become dependent on others to leverage their innovation. The systemic nature of the technology being standardized is an essential factor in both the Android project and OMA. The systemic nature of the technology and the need for cooperation leads to an open innovation process within the two cases.

Innovation in mobile telecommunication is constrained by the need for compatibility standards (West 2006). To be used, an innovation is incorporated in a formal specification/standard and these specifications are then implemented in products that are purchased by consumers and/or other producers. According to Gassmann (2006), the more the trends of globalization, technology intensity, technology fusion (industry crossover), new business models, and knowledge leveraging are present in an industry, the more appropriate the open innovation model seems to be. These traits can all be found in the mobile telecommunication industry.

With the $3 \mathrm{G}$ infrastructure being globalized and becoming an environment where people have to team up to leverage their inventions, standardization has become the arena where much of the collaboration is taking place. Standardization has then become an arena for open innovation in the mobile telecommunication domain.

There is a close relationship between the innovation system in mobile telecommunication and the standards making process. Lately it has been argued that the development of standards is the focal point for the changes in the mobile industry (King and Lyytinen 2002; Tilson and Lyytinen 2006; Yoo et al. 2005) and that there are three areas that shape and are shaped by the standards making process. These areas are the innovation process, the market place, and the regulatory regime. Together with standardization activities, it is argued that these three areas make up the new institutional environment for the $3 \mathrm{G}$ mobile infrastructure (Tilson and Lyytinen 2006). This shows the connection between standardization and the innovation process (see Figure 4).

Tilson and Lyytinen (2006) also argue that the innovation systems involves more actor groups and have become more complex and global for the $3 \mathrm{G}$ mobile infrastructure. The interconnection and the systemic nature of the infrastructure make it hard for any single firm to provide services and products unilaterally. 


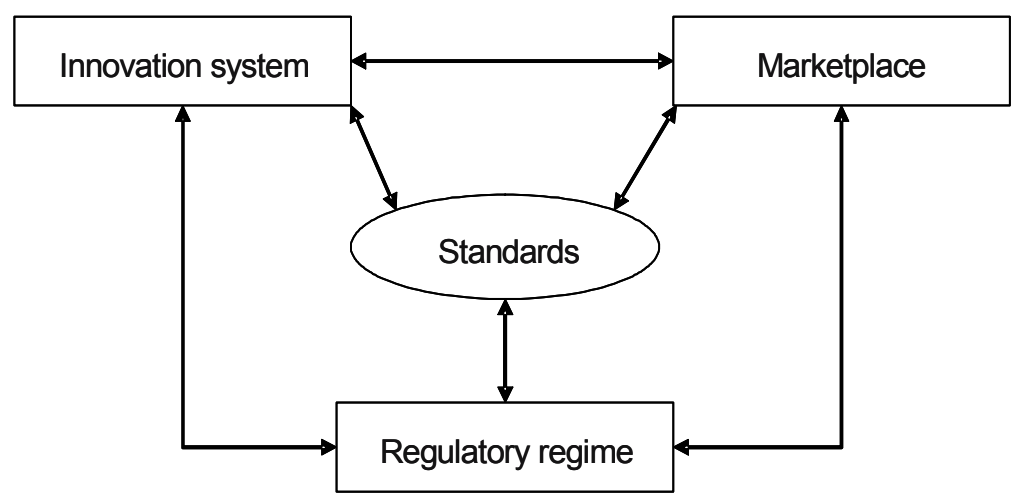

Figure 4. The Institutional Environment for the Mobile Industry (illustrating the connection between the innovation system and standards making)

As stated earlier, the cases encompass all the sources of innovation envisioned by von Hippel (1988). They have a mix of lead users, manufacturers, and suppliers. Both cases are governed by formal agreements between the participants. These are not closed but open processes, even if the OMA process was more open at the start than the Android project.

Dividing the infrastructure into three simple layers - the physical (infrastructure), code (logical infrastructure), and content layers (Benkler 1998; Lessig 2002) — one can see some differences in how additional innovation is taking place. OMA is placing their activities on the logical layer, creating standards for components that can enhance this layer. The innovation takes place on the logical layer where the participants compete to make the best implementation of the different pieces that OMA specifies for that layer. In OMA, what to build is being defined. How to implement the standards is up to the individual firms. Each component in the defined architecture (on the logical layer) can be provided by firms that have the capacity to develop it. An implementation of the architecture (the logical layer) is not provided. It is up to the individuals to realize the architecture. The Android project, on the other hand, presents a "complete" logical layer (architecture) and the innovation will take place on the content layer (architecture). This is similar to the development of new services on the Internet. The Android project provides third parties with a toolkit so they can develop new applications (new content) on top of the infrastructure. The Android model is similar to the Internet development model while OMA's approach is more in line with the telecommunication approach. As one OMA member said, "OMA creates mostly middleware while Android is higher in the stack."

In both cases, some sort of architecture/infrastructure is being specified within which the different participants can find their position. This is one of the features of open innovation (Chesbrough 2003).

Simcoe (2006) argues that changes in the nature of the innovation process, particularly an increase in the number of specialized technology developers whose business models rely heavily on intellectual property, have lead to an increasingly contentious (quarrelsome) standard setting process. He also argues that the emergence of innovation 
systems characterized by open innovation has pushed the participants in standards setting away from the "cooperate on standards and compete on implementation" mode that used to govern compatibility standardization toward a less cooperative standards creation environment, the main factor being that more firms are specializing and rely on the licensing of their technologies to capture value. They just provide components, not end products.

Intellectual property is an important theme in standardization. OMA and the Android project have taken on two different approaches in this regard. OMA relies on the traditional "reasonable and nondiscriminatory terms" model while the Android project relies on an open source licensing. So far, no handsets with the Android specifications have been launched so it is too early to say which licensing scheme works best. This is an interesting future research theme. In the Android project, the intellectual property issue is circumvented altogether with the use of an open source licensing. In OMA, there are some discussions on IPR but every OMA session starts with a call for IPR and there is strong internal pressure on the participants on being cooperative in licensing their technology (Grøtnes 2007). Both cases use IPR differently than the closed innovation model where the IPR is held inside the firm.

\section{CONCLUSION}

The key argument in this paper is that anticipatory standardization in the mobile telecommunication domain has become an arena for open innovation. This is due to the systemic character of the technology being standardized and the lack of actors that can provide all parts of the value chain. Firms must collaborate to provide a complete system.

Both the Android project and OMA innovate within a complex system where the development has a systemic nature. These systems are characterized by the interdependence between different components of the system. Innovations can typically not be promoted without the use of some other innovation provided by another actor (Maula et al. 2006). The systemic nature of the technology leads to cooperation and an open innovation process. Standardization has traditionally been the arena for cooperation in the telecommunication sector. This is also the case here and the cooperation necessary to specify the complex and global components of the $3 \mathrm{G}$ systems that OMA and Android provides is taking place within standardization. Anticipatory standardization has become an arena for open innovation in the mobile telecommunication domain.

Both cases have a purposely inbound flow of intellectual property rights, knowledge, and technical know-how. Together with this inbound flow they use their shared knowledge to generate new specifications in a cooperative environment. They provide their specifications to the public for use in further innovation. They also build architectures and systems within which to position their innovation. This is also the defining characteristics of the open innovation model.

The initial openness of the process and how firms position themselves in the infrastructures differs. This shows that open innovation can take on different forms in anticipatory standardization. In OMA, firms competes within the architecture and standards they specify, while in the Android project, firms compete on top of the archi- 
tecture they specify. In OMA, the process of defining the architecture and the components is done in cooperation in an open environment with open participation. In Android, the architecture was defined by Google and some key partners; this is also a cooperative development but with closed participation. Both are examples of open innovation processes with inbound flow of technology and intellectual property and an outbound flow of intellectual property and technology.

Viewing anticipatory standardization as an open innovation process gives a new dimension to how we reason about standardization. It is no longer a place where firms choose technology in hindsight but an arena where innovation is taking place. To function as an arena for open innovation, the technology being standardized needs to have a systemic nature.

\section{References}

Armstrong, M. 2006. “Competition in Two-Sided Markets," RAND Journal of Economics (37:3), pp. 668-691.

Bekkers, R., Verspagen, B., and Smits, J. 2002. "Intellectual Property Rights and Standardization: The Case of GSM,” Telecommunications Policy (26:3/4), pp. 171-188.

Benkler, Y. 1998. "Communications Infrastructure Regulation and the Distribution of Control Over Content," Telecommunications Policy (22:3), pp. 183-196.

Cargill, C. 1989. Information Technology Standardization: Theory, Process, and Organizations, Newton, MA: Digital Press.

Chesbrough, H. 2003. Open Innovation: The New Imperative for Creating and Profiting from Technology, Boston: Harvard Business School Press.

Chesbrough, H. 2006. "Open Innovation: A New Paradigm for Understanding Industrial Innovation," in Open Innovation: Researching a New Paradigm, H. Chesbrough, W. Vanhaverbeke, and J. West (eds.), Oxford, England: Oxford University Press, pp. 1-12.

Chesbrough, H., and Crowther, A. K. 2006. "Beyond High Tech: Early Adopters of Open Innovation in Other Industries," R\&D Management (36:3), pp. 229-236.

Christensen, C. M., and Rosenbloom, R. S. 1995. "Explaining the Attacker's Advantage: Technological Paradigms, Organizational Dynamics, and the Value Network," Research Policy (24), pp. 233-257.

Creswell, J. W. 2003. Research Design: Qualitative, Quantitative and Mixed Methods Approaches, Thousand Oaks, CA: Sage Publications.

David, P. A., and Greenstein, S. 1990. "The Economics of Compatibility Standards: An Introduction to Resent Research," Economic of Innovation and New Technology (1), pp. 3-41.

Dittrich, K., and Duysters, G. 2007. "Networking as a Means to Strategy Change: The Case of Open Innovation in Mobile Telephony," Journal of Product Innovation Management (24:6), pp. 510-521.

Dodgson, M., Gann, D., and Salter, A. 2006. "The Role of Technology in the Shift Towards Open Innovation: The Case of Procter \& Gamble," R\&D Management (36:3), pp. 333-346.

Funk, J. L., and Methe, D. T. 2001. "Market- and Committee-Based Mechanisms in the Creation and Diffusion of Global Industry Standards: The Case of Mobile Communication," Telecommunications Policy (30), pp. 589-610.

Gassmann, O. 2006. "Opening Up the Innovation Process: Towards an Agenda," R\&D Management (35:3), pp. 223-228.

Grøtnes, E. 2007. "The Creation of Standards: The Work of an International Standardization Organization," in Proceedings of the Fifth IEEE Conference on Standardization and Innovation in Information Technology, P. Feng, D. Meeking, and R. Hawkins (Eds.), Calgary, Alberta, Canada, October 18-19. 
Hawkins, R. 1999. "The Rise of Consortia in the Information and Communication Technology Industries: Emerging Implications for Policy,” Telecommunications Policy (23), pp. 159-173.

Helft, M., and Markov, J. 2007. "Google Introduces Software for New Phones," International Herald Tribune, Technology \& Media Section, November 5.

Hess, M., and Coe, N. C. 2006. "Making Connections: Global Production Networks, Standards and Embeddedness in the Mobile-Telecommunications Industry," Environment and Planning A (38:7), pp. 1205-1227.

King, J. L. and Lyytinen, K. 2002. “Around the Cradle of the Wireless Revolution: The Emergence and Revolution of Cellular Telephony," Telecommunications Policy (26), pp. 97-100.

Lessig, L. 2002. The Future of Ideas, New York: Vintage Books.

Li, F., and Whalley, J. 2002. "Deconstruction of the Telecommunications Industry: From Value Chains to Value Networks," Telecommunications Policy (26:9/10), pp. 451-472.

Lyytinen, K., Keil, T., and Fromin, V. V. 2008. "A Framework to Build Process Theories of Anticipatory Information and Communication Standardizing," International Journal of IT Standards and Standardization Research (6:2), pp. 1-38.

Maula, M., Keil, T., and Salmenkaita, J-P. 2006. Open Innovation in Systemic Innovation Contexts in Open Innovation: Reserching a New Paradigm, H. Chesbrough, W. Vanhaverbeke, and J. West (eds.), Oxford, England: Oxford University Press, pp. 241-257.

OHA. 2007. "Member Quotes," Open Handset Alliance (http://www.openhandsetalliance.com/ member quotes.html, accessed March 25, 2008).

OMA. 2005. "Memorandum and Articles of Association," Open Mobile Alliance Ltd. (http://www.openmobilealliance.org/document/Articles_of_Association_2006.pdf).

OMA. 2008. "Converged IP Messaging Architecture," Open Mobile Alliance, document OMA-AD-CPM-v1_0-20080118-D, January 18 (http://member.openmobilealliance.org/ $\mathrm{ftp} /$ Public_documents/MWG/MWG-CPM/Permanent_documents/; retrieved March 1, 2008).

Piller, F. T. , and Walcher, D. 2006. "Toolkits for Idea Competitions: A Novel Method to Integrate Users in New Product Development," $R \& D$ Management (36:3), pp. 307-318.

Prugl, R., and Schreier, M. 2006. "Learning from Leading-Edge Customers at the Sims: Opening Up the Innovation Process Using Toolkits," $R \& D$ Management (36:3), pp. 237-250.

Schmidt, S. K., and Werle, R. 1998. Coordinating Technology: Studies in the International Standardization of Telecommunications, Cambridge, MA: MIT Press.

Schwandt, T. A. 1994. "Constructivist, Interpretivist Approaches to Human Inquiry," in Handbook of Qualitative Research, N. K. Denzin and Y. S. Lincoln (eds.), London: Sage Publications, pp. 118-137.

Simard, C., and West, J. 2006. "Knowledge Networks and the Geographic Locus of Innovation," in Open Innovation: Researching a New Paradigm, H. Chesbrough, W. Vanhaverbeke, and J. West, Oxford, UK: Oxford University Press, pp. 220-240.

Simcoe, T. S. 2006. "Open Standards and Intellectual Property Rights,"in Open Innovation: Researching a New Paradigm, H. Chesbrough, W. Vanhaverbeke, and J. West, Oxford, UK: Oxford University Press, pp. 161-183.

Steinbock, D. 2005. The Mobile Revolution: The Making of Mobile Services Worldwide, London: Kogan Page.

Teece, D. J. 1986. "Profiting from Technological Innovation: Implications for Integration, Collaboration, Licencing and Public Policy," Research Policy (15), pp. 285-305.

Tilson, D., and Lyytinen, K. 2006. "The 3G Transition: Changes in the US Wireless Industry," Telecommunications Policy (30), pp. 569-586.

van de Vrande, V., Lemmens, C., and Vanhaverbeke, W. 2006. "Choosing Governance Modes for External Technology Sourcing," R\&D Management (36:3), pp. 347-363.

Vanhaverbeke, W. 2006. "The Inter-organizational Context of Open Innovation," in Open Innovation: Researching a New Paradigm, H. Chesbrough, W. Vanhaverbeke, and J. West, Oxford, UK: Oxford University Press, pp. 205-219. 
Vanhaverbeke, W., and Cloodt, M. 2006. "Open Innovaation in Value Networks," in Open Innovation: Researching a New Paradigm, H. Chesbrough, W. Vanhaverbeke, and J. West, Oxford, UK: Oxford University Press, pp. 258-281.

von Hippel, E. 1988. The Sources of Innovation, New York: Oxford University Press.

von Hippel, E., and von Krogh, G. 2006. "Free Revealing and the Private-Collective Model for Innovation Incentives," $R \& D$ Management (36:3), pp. 295-306.

Weiss, M. B. H., and Sirbu, M. 1990. "Technological Choice in Voluntary Standards Committees: An Empirical Analysis," Economic of Innovation and New Technology (1), pp. 111-133.

West, J. 2006. "Does Appropriability Enable or Retard Open Innovation," in Open Innovation: Researching a New Paradigm, H. Chesbrough, W. Vanhaverbeke, and J. West, Oxford, UK: Oxford University Press, pp. 109-133.

West, J. 2007. "Seeking Open Infrastructure: Contrasting Open Standards, Open Source and Open Innovation," First Monday (12:6) (http://www.firstmonday.org/issues/issue12_6/west/).

West, J., and Gallagher, S. 2006. "Challenges of Open Innovation: The Paradox of Firm Investment in Open-Source Software," R\&D Management (36:3), pp. 319-331.

Yoo, Y., Lyytinen, K., Yang, H. 2005. "The Role of Standards in Innovation and Diffusion of Broadband Mobile Services: The Case of South Korea," Journal of Strategic Information Systems (14), pp. 323-353.

\section{About the Author}

Endre Grotnes is at present a Ph.D. researcher at the University of Oslo and has a master of Informatics from that institution. Before embarking on his doctoral studies, Endre worked for many years in both the private and public sector where he developed guidelines and recommendations for the use of standards and technology within the Norwegian government. He has actively participated in standards organizations such as the Internet Engineering Task Force (IETF), World Wide Web consortium (W3C), European Telecommunications Standards Institute (ETSI), the European Committee for Standardization (CEN), the Open Group and the Open Mobile Alliance. His primary research interests are standardization, open source, and organizational innovation. Endre can be reached at endregr@ifi.uio.no. 